Annals of Glaciology $3 \quad 1982$

(c) International Glaciological Society

\title{
FLOW OF ICE SHEETS IN THE VICINITY OF
}

\section{SUBGLACIAL PEAKS}

by

\author{
G. de Q. Robin and D. H. M. Millar
}

(Scott Polar Research Institute, University of Cambridge, Cambridge CB2 1 ER, England)

ABSTRACT

Although changes of surface slope across a subglacial peak can be explained at least semi-quantitatively on a two-dimensional basis in terms of gradients of longitudinal and shear stresses along a flow line, we lack appreciation of flow in the third dimension which may tend to cause lower layers to flow around rather than over a sharp peak. This paper collects and surveys evidence relevant to flow in the third dimension and discusses the processes involved, particularly the evidence from radio-echo layering, and also discusses possible reasons for the lack of radio-echo layers near the base of the Antarctic ice sheet.

\section{INTRODUCTION}

Evidence from the deformation of radio-echo layers on the flow patterns within ice sheets has not yet been fully exploited. Studies by Robin and others (1969) and Whillans (1976) show layering as depositional in nature. Hammer and others (1980) and Millar (1981) have explained this by demonstrating that a principal cause of layer echoes are layers of acidic ice containing volcanic impurities. In this paper, we describe layering in a variety of ice-flow and bedrock topography conditions, with particular reference to the three-dimensional flow of the ice around bedrock obstacles. Relevant observations from ice-fabric studies and seismic reflection work are summarized, and used as evidence for a model of ice flow in the lower part of ice sheets, which involves considerable changes of flow near the boundary between the upper, more rigid ice and the lower, warmer ice. Below the boundary, the stress and strain-rate systems are considerably influenced by bedrock relief, whereas above the boundary the dominant influence is that of the regional surface slope, al though flow at all levels responds to a smoothed bedrock relief. The more variable deformation pattern in the basal layer causes the reflecting layers seen on radio-echo records to disappear in the basal zone.

\section{RADIO-ECHO LAYERING}

Radio-echo layers are commonly observed to lie parallel to the ice surface in the upper part of the ice sheet and to become progressively aligned with the bedrock in the lower parts. In the vicinity of centres of outflow in the Antarctic, layering is often observed to extend very close to bedrock (Fig.1). Moving away from a centre of outflow or an ice divide, horizontal motion becomes significant, and we observe an echo-free zone near to bedrock, as previously reported by Robin and others (1977). This zone, which is generally several hundred metres thick, is widespread in East Antarctica and probably also in West Antarctica.

To demonstrate that the lack of reflections in this zone is not simply due to inadequate system sensitivity, we look at returned power levels as well as the more familiar Z-scope recordings. The depth

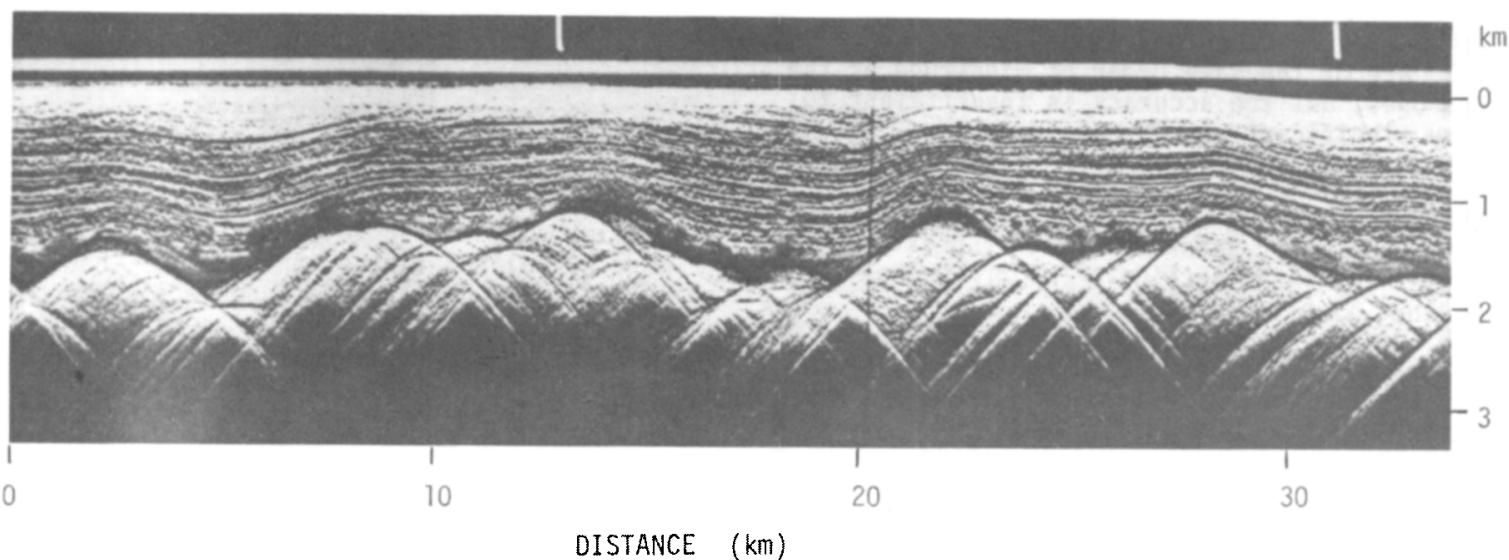

Fig.1. Radio echo-sounding Z-scope record from near Dome B, showing layering to bedrock (see Figure 3 for location). 
limits, to which internal surfaces of given reflection coefficient may be detected with the radar, may be calculated as described in Robin and others (1969) and el sewhere, and depend on observed or calculated temperature profiles and values of the temperaturedependent absorption coefficient. In central East Antarctica, we have been able to check these absorption estimates, using a smooth ice/water interface above a subglacial lake near Vostok, for which the reflection coefficient may be estimated within narrow limits. Good agreement between observed and calculated absorption losses suggests that our calculated figures are normally not more than a few $d B$ in error. Where layering disappears due to absorption losses, we observe that the cut-off for layering at a particular site varies with reflection coefficient, strongly reflecting layers being detectable to greater depths than weaker ones, and this closely matches the predicted system detection 1 imit. However, at many East Antarctic sites there is a sharp cut-off in layer echoes at a boundary well above the calculated detection limit (Fig.2(a)). This clearly indicates that suitable reflecting surfaces are absent below this level.

The extent and nature of this echo-free zone near an ice divide is shown in Figure 2(b), which shows selected layering along 1 ines $A A^{\prime}$ and $B B^{\prime}$ ' (see Fig.3 for locations), together with estimated maximum depths to which surfaces of given reflection coefficient are expected to be seen with the radar. We note that most echoes below $\sim 600 \mathrm{~m}$ in Figure $2(\mathrm{a})$ have reflection coefficients of about $-80 \mathrm{~dB}$, so we attribute absence of layering in the basal ice of Figure $2(b)$ to the absence of suitable reflecting surfaces. As one moves to deeper and/or warmer ice, absorption losses limit the depth of observed layering more frequently, and this is the case for most of the interior of West Antarctica.

At many sites where such an echo-free zone is clearly developed (Fig.4), we al so observe a transition zone between it and the layering above it of 100 to $200 \mathrm{~m}$ thickness, containing "broken-up" layering with very short horizontal continuity, and nearvertical cusps or "fingers" (Harrison 1973). This indicates the presence of reflectors dipping fairly

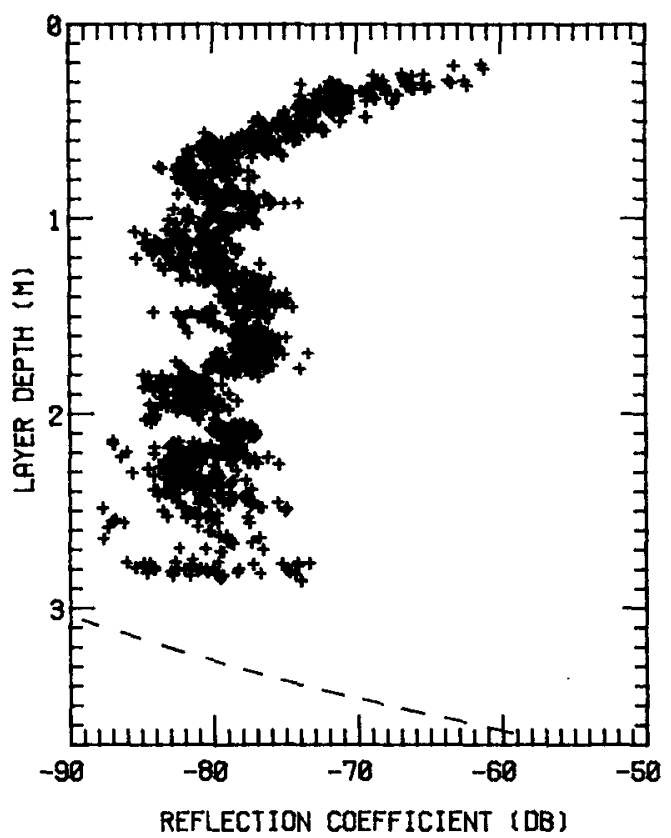

Fig.2(a). Layer reflection coefficient vs depth from many observations of 1 ayer echoes at site on line $A A^{\prime}$, and calculated system detection limit, indicating the existence of a basal echo-free zone.
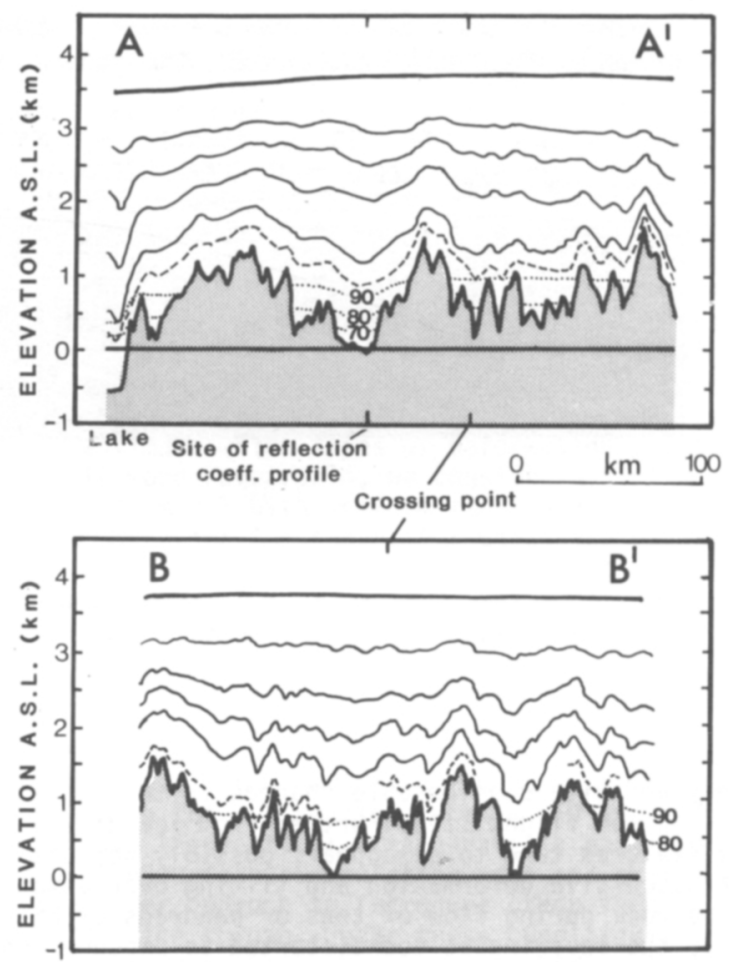

Fig.2(b). Profiles showing positions of selected radio-echo layers and surface and bedrock topography along lines down a flow line from the ice divide above Vostok ( $\left.A A^{\prime}\right)$ and along the crest of the ice divide $\left(B B^{\prime}\right)$. Dashed line represents the lowest visible layer; dotted lines represent calculated maximum depths to which surfaces with reflection coefficients of $-70,-80$, and $-90 \mathrm{~dB}$ may be seen with the radar.

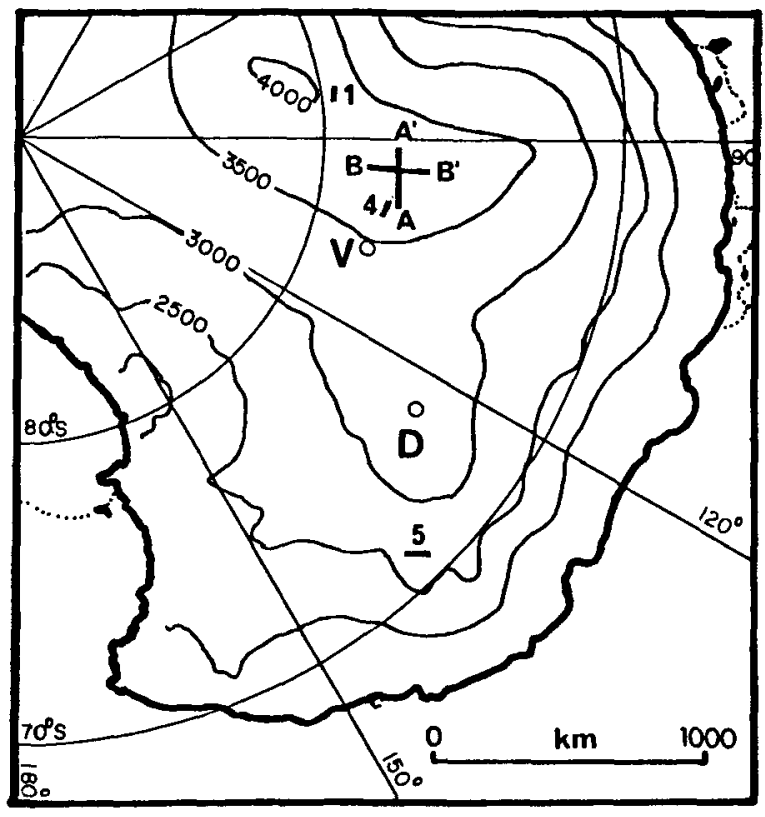

Fig.3. Location map for 1 ayering examples and surface contours. V: Vostok, $D$ : Dome $C$ camp, 1: site of record in Figure $1, A A^{\prime}, B B^{\prime}$ : profiles in Figure 2(b), 4: site of record in Figure 4, 5: site of record in Figure 5 . 


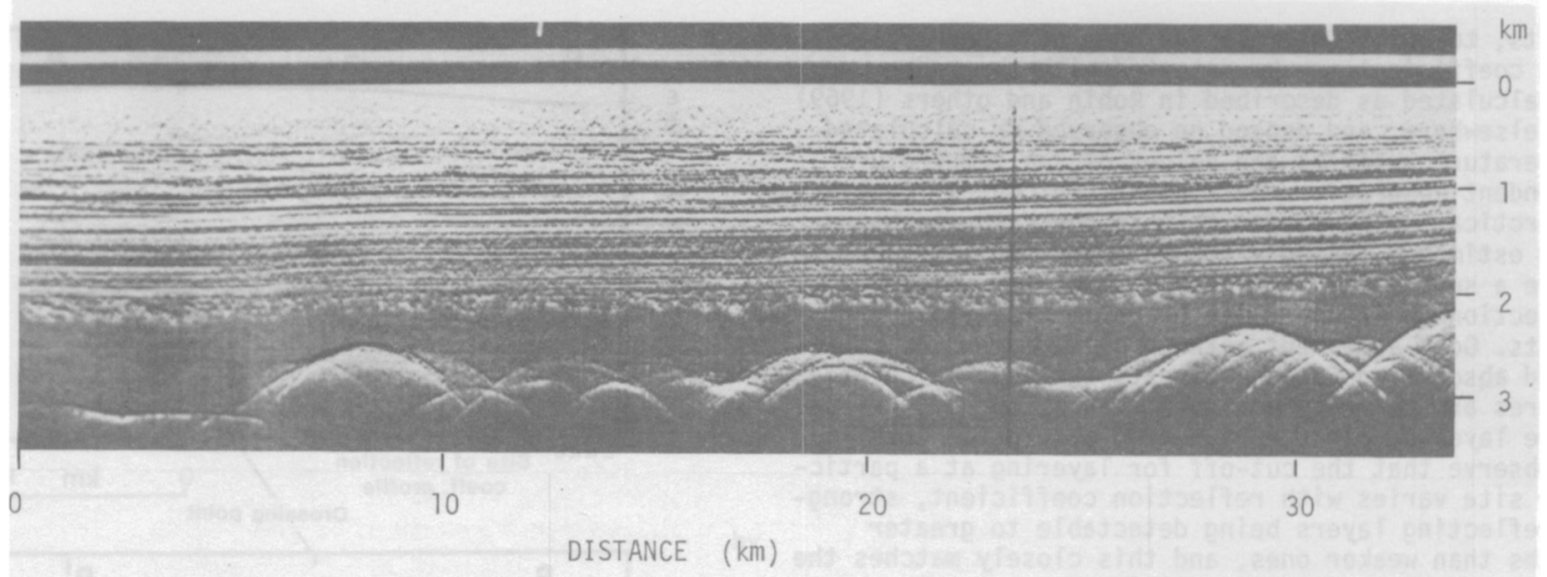

Fig.4. Radio echo-sounding $Z$-scope record along flow line above Vostok, showing basal echo-free zone, transition zone containing cusps and "finger" effects, and continuous layering above.

steeply and with considerable changes in the plane of dip along the flight line. Further from ice divides, these features tend to disappear, possibly because, after successive deformation and tilting over a variable bedrock during flow of tens or hundreds of kilometres, the layering is too distorted to produce consistent or recognizable cusps.

It has been pointed out in Robin and others (1977) that deformation between visible layers is approximately uniform through the ice sheet, but, between the lowest visible layer and bedrock, deformation must be very variable as the lowest layers often do not follow the bedrock closely. This indicates that the flux of ice across deeper parts of the relief will be greater, and that ice flow must be diverted into these valleys from either side of the flow line. It appears that this diversion of flow takes place throughout the thickness of the ice.

Clear evidence of the extent of a net sideways component of flow near bedrock comes from flights along surface contours in areas of smooth bedrock (Fig.5). Here we see that the layering has retained considerable undulations both from single large obstacles ( 10 to $15 \mathrm{~km}$ in the figure) and from complex flow over irregular high relief further up the flow line $(50$ to $80 \mathrm{~km})$. The retention of these features under steady flow conditions after the ice has passed the obstacles suggests some net transverse flow of ice at lower levels when passing obstacles, rather than simply uniform vertical deformation over an obstacle with no resultant sideways ice movement.

\section{ICE-FABRIC STUDIES}

The development of a strongly oriented ice fabric with vertical c-axes occurs in the Byrd ice core between 1000 and $1810 \mathrm{~m}$ (Gow and Williamson 1976), below which the fabric is composed of "several discrete maxima generaliy arranged in a ring-like fashion around the vertical". Gow and Kohnen (1979) measured ultrasonic P-wave velocities both along and normal to the axis of the core and found a sudden drop of $\sim 100 \mathrm{~m} \mathrm{~s}^{-1}$ between 1780 and $1830 \mathrm{~m}$, which, they believe, corresponds to a change in ice fabric. The maximum depth of radio-echo layering observed when flying over the borehole site was $1800 \mathrm{~m}$, but this is so close to the absorption limit that we are uncertain whether or not this marks the upper limit of the echo-free zone previously mentioned.

On the Law Dome, Russell-Head and Budd (1979) found the highest horizontal shear rates at the lowest level of a zone containing a high concentration of vertical c-axes, and conclude that "the shear stress must decrease towards the bed after reaching a maximum in the region of the high shear layer located at about two-thirds of the ice thickness". They also suggest that the echo-free basal zone noted by Robin and others (1977) may bear some relation to this slowly deforming basal layer.

The presence of additional acid impurities in the ice layers from which radio reflections are observed (Millar 1981) may also affect the mechanical properties. Laboratory studies (Jones and Glen 1969) show that the addition of very small amounts of HF to pure

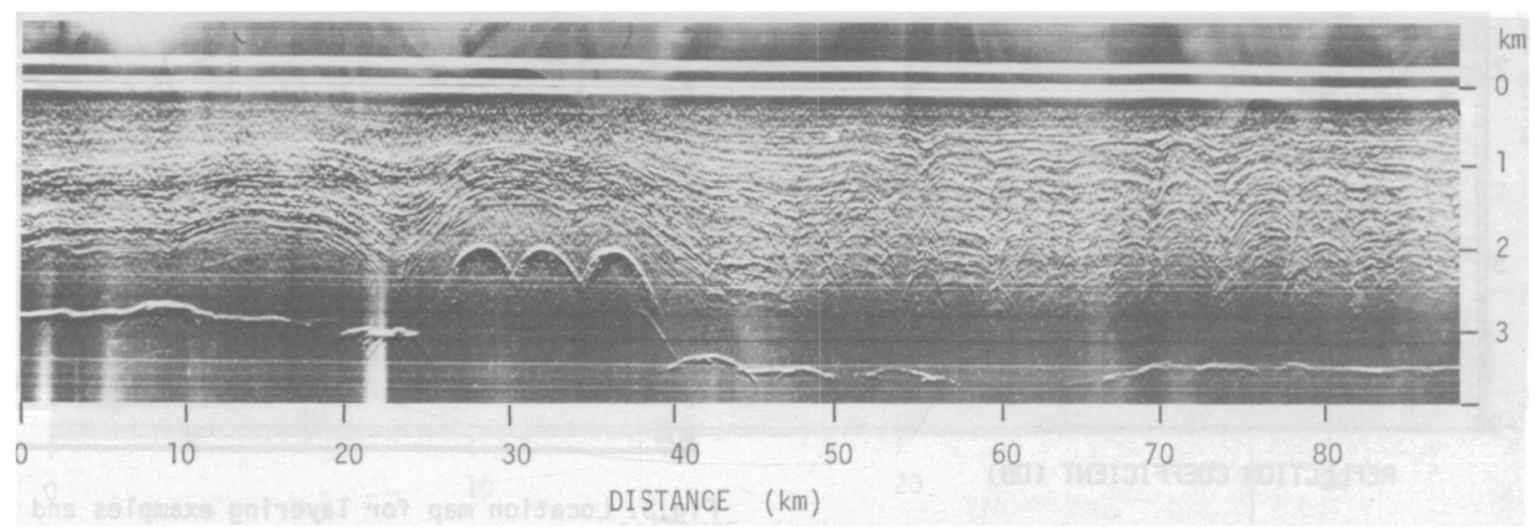

Fig.5. Radio echo-sounding Z-scope record along surface contour at site in East Antarctica (see Fig.3), showing undulations in layering believed caused by flow round bedrock obstacles up-stream. 
ice causes appreciable softening; hence, it is possible that, when a strongly oriented fabric with a near-vertical $c$-axis is formed, the radio-echo layers indicate the easy glide $p$ lane and hence the icefabric orientation. It does not follow that all radioecho layers do so, but that they may if such orientation is present, as at Byrd.

\section{BASAL SEISMIC REFLECTING LAYER}

Bentley (1971) has reported a widespread low amplitude seismic reflecting layer in West Antarctica, commonly of 200 to $400 \mathrm{~m}$ thickness above the bed. His observations show not only a single reflection from the top of this basal layer, but, at times, weaker reflections closer to bedrock within the layer. We have not been able to 1 ink this directly with observations of the radio-echo layer-free zone due to high absorption losses in West Antarctica; however, the thicknesses of the two types of layer are similar.

Bentley proposed three possible explanations: moraine within the ice, changes of ice fabric, or a layer of isothermal ice at the pressure-meiting point. The first was his preferred explanation, but the Byrd ice core showed that moraine was confined to the lowest few metres of the ice, whereas, at 01d Byrd station (15 $\mathrm{km}$ distant), the seismic reflecting layer extended to $460 \mathrm{~m}$ above bedrock in $2480 \mathrm{~m}$ thick ice. Temperature measurements in the Byrd bore hole do not show a layer of isothermal ice near to bedrock, and we conclude that ice-fabric changes provide a general explanation rather than one applying to a few sites only, as suggested by Bentley. The seismic wavelength of $\sim 40 \mathrm{~m}$, together with a change in $\mathrm{P}$-wave velocity of $\sim 100 \mathrm{~m} \mathrm{~s}^{-1}$ over 5 to $10 \mathrm{~m}$, should produce a reflection of $11.5 \%$ of the incident wave amplitude. Measured amplitude ratios 1 ay in the range 0.3 to $13 \%$.

\section{DISCUSSION}

The observations presented above are all consistent with the following model, parts of which have been suggested in earlier studies in a two-dimensional context by several authors.

At centres of outflow, firn and ice are deposited with random crystal orientation, but, as flow and internal shear develop with increasing ice velocity, a strongly oriented fabric with a vertical c-axis develops (Whillans 1979), so that flow is enhanced by a near-horizontal easy-glide plane at depths down to the basal layer. Below this, a multi-polar fabric (Gow and Williamson 1976) is caused by recrystallization, which, we suggest, is due to changes of stress and strain directions in three dimensions in response to varying bedrock slopes. If the interface between the two fabrics is sharp enough, it may produce the seismic reflections observed by Bentley over wide areas of West Antarctica, and also mark the level at which internal horizons become heavily deformed and radio-echo layering disappears. We envisage the ice sheet as comprised of fairly rigid but isotropic ice in the upper layers (accounting for perhaps $30 \%$ of the ice thickness), a central 1ayer with strong vertical c-axis orientation ( 30 to $50 \%$ thickness), and a more isotropic crystal structure in the warmer basal ice ( 5 to $25 \%$ thickness). The central zone deforms mainly by shear in near-horizontal planes. Due to fabric change, there is a sharp decrease of shear below this oriented ice, as seen at Law Dome and probably at Byrd (Russe11-Head and Budd 1979) when one considers changes of uitrasonic velocities in ice core samples around this level (Gow and Kohnen 1979). The basal ice will respond more readily to the action of longitudinal and transverse stress differences than the ice above. Evidence from radioecho layering suggests this is important when bedrock slopes are of the order of $20^{\circ}$ or more.

In order to discuss flow in the basal zone in the vicinity of bedrock peaks, we use the "principle of least action" which is not often applied to the flow of glaciers. We can state the principle as: "of all possible incremental displacements in an ice mass deforming under body and external forces, those which make the incremental work done a minimum defines the deformation". If it is energetically more favourable, therefore, deformation of the basal layers of ice will involve a component of flow around a subglacial peak rather than uniform flow over the peak. If this occurs, it may affect layering downstream of the peak, since, if ice moves more readily around the peak than over the top, it may permanently distort the layering down-stream. This appears to explain the pattern of layering in Figure 5 , which is located down-stream of an area of rough bedrock topography but which has itself a smooth bed.

To estimate which types of deformation are ener-. getically more favourable, we consider a simple vertical column model with uniform strain-rate for flow in a steady-state ice sheet, for which the vertical strain-rate $\dot{\varepsilon}_{z}$ in two-dimensional flow can be written:

$$
\dot{\varepsilon}_{Z}=\frac{1}{H}\left(\dot{A}-u \frac{d H}{d x}\right),
$$

where $H$ is the total ice thickness, $\dot{A}$ the accumulation rate, and $u$ the horizontal velocity along the flow line in the $x$ direction. When $u=0$ at a centre of outflow, the vertical strain-rate is governed only by the surface accumulation rate and there is no shear over bedrock to introduce other factors to deform the ice column. Under these conditions, layering can extend to bedrock as seen in Figure 1. As soon as horizontal motion becomes significant, additional shear stress and strains are introduced, due to motion over an irregular bedrock. Typical figures for central East Antarctica may be $A=0.03 \mathrm{~m} \mathrm{a}^{-1}$ and $H=3000 \mathrm{~m}$, giving $\varepsilon_{2}=10^{-5} \mathrm{a}^{-1}$. According to Equation (1), the same strain would be introduced by horizontal movement of $1 \mathrm{~m} \mathrm{a} \mathrm{a}^{-1}$ if $\mathrm{dH} / \mathrm{dx}=3 \times 10^{-2}$. Although surface slopes are around a third of this or less, bedrock slopes are much higher. Since velocities of $1 \mathrm{~m} \mathrm{a}^{-1}$ are reached within $100 \mathrm{~km}$ of an ice divide, it appears that our vertical strain-rates could be dominated by the $\mathrm{udH} / \mathrm{dx}$ term at distances of this order from ice divides and domes. We note that the echo-free zone usually starts to develop about $50 \mathrm{~km}$ from centres of outflow.

We can also use a simple vertical column model plus observations of surface slopes in central East Antarctica to compare the relative work of deformation due to longitudinal stresses and shear stresses. We note that driving stresses which are primarily basal shear stresses average around $\tau_{b}=40 \mathrm{kPa}$ in this region (Cooper and others 1982). From Robinson (1964), we note the presence of valleys up to $60 \mathrm{~m}$ deep in the ice sheet in the vicinity of the South Pole, which implies stress differences $\left(\sigma_{z}-\sigma_{x}\right)$ around $\pm 300 \mathrm{kPa}$, in regions where ice velocity will be well below $10 \mathrm{~m} \mathrm{a}^{-1}$. Work done for horizontal motion $u$ will be utb for basal shear, and

$(\dot{A}-u d H / d x) \cdot\left(\sigma_{z}-\sigma_{x}\right)$ due to the longitudinal strain. Work by the two processes would be equal if

$$
u \tau_{b}=\dot{A}-u d H / d x\left(\sigma_{z}-\sigma_{x}\right),
$$

so, using our approximate values for the stresses, this occurs when $\mathrm{dH} / \mathrm{dx} \simeq 40 / 300=1 / 7.5$. We note on Figures $2(b)\left(A A^{\prime}\right)$ and 4 that, al though bottom siopes along flow lines appear to exceed $1: 7.5$ frequently, the slope of the deep internal layers rarely exceeds $1: 100$. Thus, qualitatively at least, it appears that the energy involved in longitudinal deformation in the ice sheet remains substantially less than that involved in basal shear. This provides at least a partial explanation of why the upper level of the basal layer shows a much lower relief than the bedrock beneath along a flow line. Furthermore, along both flow lines and surface contours, vertical deformation between the surface and deepest reflecting 
horizon appears to be approximately uniform. Thus the tendency for fiow to be diverted into sub-ice valleys running in the flow direction apparently takes place unifomly at all depths. A model which would largely satisfy this condition is one in which the longitudinal stress gradients are set up to overcome variations of basal relief and of basal shear stress, resulting in changes of surface elevation along the flow line. Where sub-ice relief on either side of the flow line is different, the elevation changes will produce surface slopes normal to the flow if ine, which, in turn, produce transverse stress differences $\left(\sigma_{z}-\sigma_{y}\right)$ that cause vertical strain throughout the whole ice column, thus diverting ice to deeper areas.

We cannot assume that the stress differences $\left(\sigma_{z}-\sigma_{x}\right)$ and $\left(\sigma_{z}-\sigma_{y}\right)$ apply in the basal ice layer, as they interact with shear stress gradients $\mathrm{d} \tau_{z x} / d x$ and $d \tau_{y z} / d y$. Rapid changes of ice fabric across this boundary would also be expected to cause rapid changes of flow. However, the lack of very rapid changes of the upper surface of the basal ice zone along flow lines, and the relative uniformity of thickness of this zone beneath surface contour lines shown on seismic reflection and radio-echo records, indicates that diversion of ice flow around subglacial peaks is not large except in the case of the steepest peaks (Fig.2(b)). In such cases, the constraint that near-bedrock ice movement must take place in planes parallel to bedrock, together with incompressibility conditions, may be sufficient to cause some ice to flow around sharp peaks, but the field evidence suggests that this is not a frequent occurrence.

\section{CONCLUSION}

While two-dimensional analyses involve a gradual transition of ice velocity from flowing parallel to the bed to flowing approximately parallel to the surface, the field evidence presented above suggests, when considered as a whole, that the transition between shear controlled by bedrock surfaces and shear controlled internally due to mean surface slope, takes place within thick ice sheets at a relatively sharp boundary around the upper limit of the radioecho non-reflecting zone.

\section{ACKNOWLEDGEMENT}

We should like to thank the US National Science Foundation for logistic support, the US Navy Squadron VX6, whose aircrews undertook the flying programme, and the UK Natural Environment Research Council for research funding. One of us (DHMM) wishes to thank NERC for support in the form of a Research Studentship.

\section{REFERENCES}

Bentley C R 1971 Seismic evidence for moraine within the basal Antarctic ice sheet. In Crary A P (ed) Antarctic snow and ice studies II: 89-129 (Antarctic Research Series 16)

Cooper A P R, McIntyre N, Robin G de Q 1981 Driving stresses in the Antarctic ice sheet. Annals of Glaciology 3: 59-64

Gow A J, Kohnen $H 1979$ The relationship of ultrasonic velocities to $c$-axis fabrics and relaxation characteristics of ice cores from Byrd Station, Antarctica. Joumal of Glaciology 24(90): 147153

Gow A J, Williamson T 1976 Rheological implications of the internal structure and crystal fabrics of the west Antarctic ice sheet as revealed by deep core drilling at Byrd Station. Geological Society of America. Bulletin 87(12): $1665-1677$

Hammer C U, Clausen H B, Dansgaard W 1980 Greenland ice sheet evidence of post-glacial volcanism and its climatic impact. Nature 288(5788): 230235
Harrison C H 1973 Radio echo sounding of horizontal layers in ice. Joumal of Glaciozogy 12(66): 383-397

Jones S J, Glen J W 1969 The effect of dissolved impurities on the mechanical properties of ice crystals. Philosophical Magazine 19(157): 13-24

Millar D H M 1981 Radio-echo layering in polar ice sheets and past volcanic activity. Nature 292(5822): 441-443

Robin G de Q, Evans S, Bailey J T 1969 Interpretation of radio echo sounding in polar ice sheets. Philosophical Transactions of the Royal Society of London Ser A 265(1166): 437-505

Robin G de Q, Drewry D J, Meldrum D T 1977 International studies of ice sheet and bedrock. Philosophical Transactions of the Royal Society of London Ser B 279(963): 185-196

Robinson E S 1966 on the relationship of icesurface topography to bed topography on the South Polar plateau. Journal of Glaciology 6(43): 4354

Russell-Head D S, Budd WF 1979 Ice sheet flow properties derived from bore-hole shear measurements combined with ice-core studies. Journal of Glaciology 24(90): 117-130

Whillans I M 1976 Radio-echo layers and the recent stability of the West Antarctic ice sheet. Nature 264(5582): $152-155$

Whillans I $M$ 1979 Ice flow along the Byrd Station strain network, Antarctica. Joumal of Glaciology $24(90): 15-28$ 